EDITORA

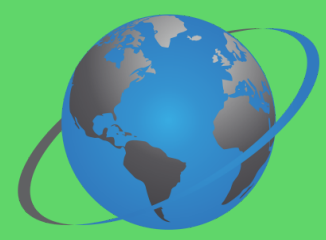

OMNIS SCIENTIA

\title{
SAÚDE PÚBLICA EM
}

\section{TEMPOS PANDEMICOS}

\section{VOLUME 1}

Organizador:

Raul Sousa Andreza

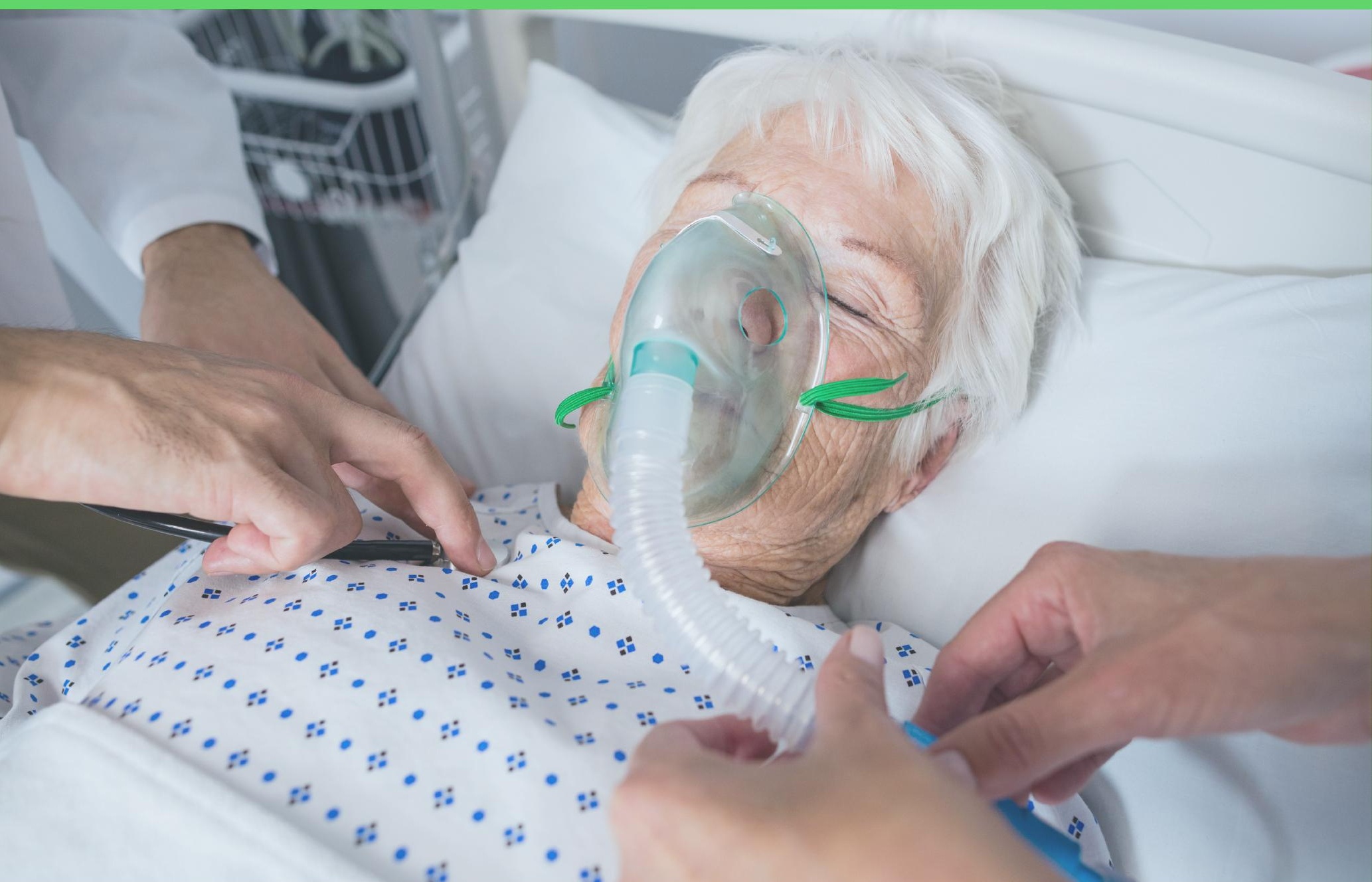


EDITORA

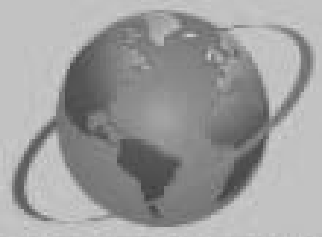

OMNIS SCIENTIA

\section{SAÚDEE PÚBUICA BM}

\section{THEMIPOS PANDENMICOS}

\section{VOLUME 1}

Organizador:

Raul Sousa Andreza

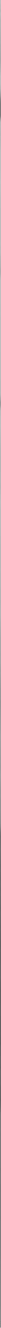


Editora Omnis Scientia

SAÚDE PÚBLICA EM TEMPOS PANDÊMICOS

Volume 1

$1^{a}$ Edição

TRIUNFO - PE

2021 


\section{Editor-Chefe}

Me. Daniel Luís Viana Cruz

Organizador (a)

Prof. Me. Raul Sousa Andreza

\section{Conselho Editorial}

Dra. Pauliana Valéria Machado Galvão

Dr. Wendel José Teles Pontes

Dr. Walter Santos Evangelista Júnior

Dr. Cássio Brancaleone

Dr. Plínio Pereira Gomes Júnior

Editores de Área - Ciências da Saúde

Dra. Camyla Rocha de Carvalho Guedine

Dra. Cristieli Sérgio de Menezes Oliveira

Dr. Leandro dos Santos

Dr. Hugo Barbosa do Nascimento

Dr. Marcio Luiz Lima Taga

Dra. Pauliana Valéria Machado Galvão

\section{Assistentes Editoriais}

Thialla Larangeira Amorim

Andrea Telino Gomes

Imagem de Capa

Freepik

\section{Edição de Arte}

Vileide Vitória Laranjeira Amorim

\section{Revisão}

Os autores

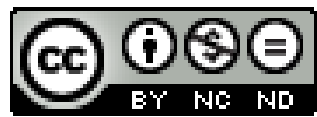

Este trabalho está licenciado com uma Licença Creative Commons - AtribuiçãoNãoComercial-SemDerivações 4.0 Internacional.

O conteúdo abordado nos artigos, seus dados em sua forma, correção e confiabilidade são de responsabilidade exclusiva dos autores. 
Dados Internacionais de Catalogação na Publicação (CIP) (eDOC BRASIL, Belo Horizonte/MG)

S255 Saúde pública em tempos pandêmicos [livro eletrônico] / Organizador Raul Sousa Andreza. - Triunfo, PE: Omnis Scientia, 2021.

286 p. : il.

Formato: PDF

Requisitos de sistema: Adobe Acrobat Reader

Modo de acesso: World Wide Web

Inclui bibliografia

ISBN 978-65-88958-41-4

DOI 10.47094/978-65-88958-41-4

1. Ciências da saúde. 2. Saúde pública. 3. Pandemia. I. Andreza, Raul Sousa.

CDD 610

Elaborado por Maurício Amormino Júnior - CRB6/2422

\author{
Editora Omnis Scientia \\ Triunfo - Pernambuco - Brasil \\ Telefone: +55 (87) 99656-3565 \\ editoraomnisscientia.com.br \\ contato@editoraomnisscientia.com.br
}




\section{PREFÁCIO}

A incidência do novo coronavírus no Brasil é preocupante. No entanto, a saúde pública do país e o sistema de atendimento visa abranger a diversidade que o Brasil apresenta, o sistema único de saúde (SUS) tem como base a integralidade, a universalidade e a equidade de todos os pacientes e trabalhadores. Instituído assim, para democratizar toda a saúde brasileira, tem o interesse de ofertar serviços de qualidade a população. Portanto, ao longo da história de sua consolidação a saúde pública foi deixado de lado e passou a gerar grandes problemas aos profissionais atuantes.

De fato, os estudos desenvolvidos no âmbito da saúde pública se propõem a articular conhecimentos de diferentes saberes e fazeres fornecendo subsídios teóricos, práticos e metodológicos que contribuem positivamente para a construção de estratégias e políticas públicas que visam o desenvolvimento de informações e ações em prol de uma saúde de qualidade para toda comunidade.

O presente livro é composto por 24 capítulos elaborados por autores pertencentes às ciências da saúde e suas áreas afins com o objetivo de proporcionar conhecimentos e compartilhar experiências e resultados de estudos desenvolvidos em várias localidades brasileiras e que visam à elucidação de diferentes situações de saúde.

Em nossos livros selecionamos um dos capítulos para premiação como forma de incentivo para os autores, e entre os excelentes trabalhos selecionados para compor este livro, o premiado foi o capítulo 02, intitulado "VACINAS CONTRA COVID-19: UMA BREVE DESCRIÇÃO POR MEIO DE REVISÃO INTEGRATIVA“. 


\section{SUMÁRIO}

CAPÍTULO 1

A IMPORTÂNCIA E OS DESAFIOS DA ESTRATÉGIA DE SAÚdE DA FAMÍLIA NO ENFRENTAMENTO DA COVID-19

Romana Erica Tavares Grangeiro Pinto

Wyara Ferreira Melo

Maria Amanda Laurentino Freires

Patrício Borges Maracajá

Aline Carla de Medeiros

José Cândido da Silva Nóbrega

Manoel Marques de Souto Nóbrega Filho

Túlio Alberto de Oliveira Sousa

Mônica Valéria Barros Pereira

Vicente Saraiva dos Santos Neto

Hozanna Estrela Celeste

Gabriela Rocha Pordeus dos Santos

DOI: 10.47094/978-65-88958-41-4/17-26

CAPÍTULO 2

VACINAS CONTRA COVID-19: UMA BREVE DESCRIÇÃO POR MEIO DE REVISÃO INTEGRATIVA

Fernanda Lima Marçal

Isabela Figueiredo e Souza

Maria Eduarda Coelho Gomes

Larissa Lima Torres

Isabela Campbell Santos

Thamara Lóren Lima

Ludmilla Vieira Magalhães

Maria Eduarda Sirina Pereira

Lucas Viana de Oliveira 
Larissa da Silva Torres França

Natan Fiorotti da Silva

Milena de Oliveira Simões

DOI: 10.47094/978-65-88958-41-4/27-41

CAPÍTULO 3

AÇÃO EM SAÚdE E A IMPORTÂNCIA DO USO CORRETO DAS MÁSCARAS PARA PREVENÇÃO DE INFECÇÕES RESPIRATÓRIAS

Soniely Nunes de Melo

Rafael Belarmino de Souza Lima

Tarcísio Correia Sposito

Rayana Ribeiro Trajano de Assis

Nayara Sandriele Santana de Souza

Bruna Rafaella Santos Torres

Flávio José Alencar de Melo

Davi Silva de Jesus

Carlos Henrique Bezerra de Siqueira

Izabelle Barbosa da Silva

Marcos André de Holanda Prudente Pessoa

Ana Marlusia Alves Bomfim

DOI: 10.47094/978-65-88958-41-4/42-51

CAPÍTULO 4

CONHECIMENTOS DAS EQUIPES MULTIPROFISSIONAIS DA ESTRATÉGIA DE SAÚDE DA FAMIILIA SOBRE COVID-19 E GESTAÇÃO

Priscilla dos Santos Nascimento

Michelle Araújo Moreira

DOI: 10.47094/978-65-88958-41-4/52-65 
CARTILHA EDUCATIVA SOBRE A COVID-19 PARA A PROTEÇÃO DA COMUNIDADE ACADÊMICA DO CAMPUS BELÉM DO IFPA

Lidineusa Machado Araujo

Maria de Nazaré Pereira Rodrigue Martins

Gabriela Priscila de Lima Carvalho

Fernanda Rafaela de Souza Rebelo da Costa

Michelle da Silva Pereira

Andréa de Melo Valente

Maria Helena Cunha Oliveira

Antônio Marcos Mota Miranda

DOI: 10.47094/978-65-88958-41-4/66-75

CAPÍTULO 6 .76

A SAÚdE DOS PROFISSIONAIS DE SAÚDE QUE ATUAM NA LINHA DE FRENTE NA PANDEMIA DO COVID - 19: REVISÃO INTEGRATIVA

João Lucas Ferreira Andrade

Léa Bianch Lima

Luana Kellen Nogueira Epitácio

Maria Eduarda Alves Vasconcelos

Antônio Augusto Ferreira Carioca

Carlos Antônio Bruno da Silva

Eudóxia Sousa de Alencar

DOI: 10.47094/978-65-88958-41-4/76-89

CAPÍTULO 7 .90

OS EFEITOS DA PANDEMIA NA COMPULSÃO ALIMENTAR: UMA REVISÃO DE LITERATURA

Lais Pontes de Miranda Cerqueira

Tarcio Goncalves sobral

Isadora Bianco Cardoso de Menezes

DOI: 10.47094/978-65-88958-41-4/90-97 
O IMPACTO DA PANDEMIA DO COVID - 19 SOBRE A SEGURANÇA ALIMENTAR E NUTRICIONAL: REVISÃO INTEGRATIVA

Bruna Sousa Barbosa

Igor Matheus Cruz de Oliveira

João Lucas Ferreira Andrade

Léa Bianch Lima

Luana Kellen Nogueira Epitácio

Maria Eduarda Alves Vasconcelos

Antônio Augusto Ferreira Carioca

Carlos Antônio Bruno da Silva

Eudóxia Sousa de Alencar

DOI: 10.47094/978-65-88958-41-4/98-104

CAPÍTULO 9 105

A UTILIZAÇÃO DOS PROTOCOLOS DE USO DO GUIA ALIMENTAR PARA A POPULAÇÃO BRASILEIRA: RELATO DE EXPERIÊNCIA

Bárbara Santos Amorim

Lis Chaves Marinho

Isadora Bianco Cardoso de Menezes

DOI: 10.47094/978-65-88958-41-4/105-114

CAPÍTULO 10 .

O IMPACTO DA COVID-19 EM PORTADORES DE SÍNDROME METABÓLICA

Laura Rasul de Lima

Ana Beatriz Amaral Vieira

Gabriella Neiva Reis

Ingrid Ravenna Liberalino Lima

DOI: 10.47094/978-65-88958-41-4/115-122 
SIMPLIFICANDO A HANSENÍASE: PROJETO DE INTERVENÇÃO REALIZADO EM

MEIO DIGITAL DURANTE A PANDEMIA

Amanda Almeida Lima

Ana Beatriz Sousa Santos

Francisco Vittor Miranda e Araújo

Jesamar Correia Matos Filho

João Ferreira de Paula Neto

Maria Clara de Freita Albano

Manoel Cícero Viana de Lima

Pedro Schmitt Martins Paiva Matos

Ruddy Mariano Maia Cysne Guerra

Samuel Carvalho Vasconcelos

Thaine Mirla Rocha

Elaine Lopes Bomfim

DOI: 10.47094/978-65-88958-41-4/123-131

CAPÍTULO 12.

DESCOMPLICANDO A HANSENÍASE: PROJETO DE INTERVENÇÃO REALIZADO EM UNIDADE DE SAÚDE NO PERÍODO DA PANDEMIA

Adália Stefanny de Araujo Cavalcante

Giovanna Giffoni Souza do Nascimento

Iêda de Freitas Martins Jota

Isabel Camila Araújo Barroso

Kaio Rangel Freitas Guimarães

Laís Mesquita de Sousa

Monique dos Santos Chaves

Manoel Victor Freires Vieira

Matheus Macedo Braga Coelho

Thaine Mirla Rocha

Elaine Lopes Bomfim 
CAPÍTULO 13. 140

HANSENÍASE: UM ESTUDO EPIDEMIOLÓGICO NA REGIÃO DO MÉDIO ARAGUAIAMATO GROSSO

Flavia Rodrigues Santana

Josilene Dália Alves

DOI: 10.47094/978-65-88958-41-4/140-150

CAPÍTULO 14 151

MUNICÍPIOS COM ALTA INCIDÊNCIA DE TUBERCULOSE EM MATO GROSSO: CONHECER PARA INTERVIR EM TEMPOS DE PANDEMIA

Larissa Machado Bellé

Yasmim Paloma Abreu Silva

Alessandro Rolim Scholze

Josilene Dália Alves

DOI: 10.47094/978-65-88958-41-4/151-162

CAPÍTULO 15 163

SAÚDE INTEGRAL DA MULHER EM CONTEXTO PANDÊMICO: REVISÃO INTEGRATIVA DE LITERATURA

Lohana Guimarães Souza

Tailande Venceslau Carneiro

Letícia Grazielle Santos

DOI: 10.47094/978-65-88958-41-4/163-175

CAPÍTULO 16 176

ASSISTÊNCIA DE ENFERMAGEM NO OUTUBRO ROSA E PERFIL EPIDEMIOLÓGICO DAS MULHERES: RELATO DE EXPERIÊNCIA

Helena Pereira de Souza

Laura Letícia Perdição Guerra

Luana Fernandes e Silva 
Thales Philipe Rodrigues da Silva

Alessandra Lage Faria

Helen Carine Ferreira Balena

Érica Moreira de Souza

Bruna Luíza Soares Pinheiro

Lorena Medeiros de Almeida Mateus

Flávia Duarte de Oliveira Ribeito

Bianca Maria Oliveira Luvisaro

Fernanda Penido Matozinhos

DOI: 10.47094/978-65-88958-41-4/176-188

CAPÍTULO 17 189

AGRAVAMENTO DAS DOENÇAS PSIQUIÁTRICAS DURANTE O PERÍODO DE ISOLAMENTO SOCIAL: UMA BREVE REVISÃO DE LITERATURA

Hellen Kristina Magalhães Brito

Gabriela Teixeira Lima

Ana Laura Fernandes Tosta

Laura Beatriz Caitano de Oliveira

Maria Paula Ricardo Silva

Mariana Vieira Garcia de Carvalho

Nathália Siriano Costa

Mayara Rita Figueredo

Mabel Fernandes Rocha

Helena Maria Mendes Marques

Kaio Murilo Santana Corrêa

Ana Flávia Buiatte Andrade

DOI: 10.47094/978-65-88958-41-4/189-200 
ATUAÇÃO DO PSICÓLOGO EM TEMPO DE PANDEMIA: UMA REVISÃO DE ESTUDOS NACIONAIS

Gabriel Rigamonte

Sueli Souza

Wilson Quiroz

Daniel Bartholomeu

Fernando Pessotto

Cintia Heloína Bueno

Fernanda Helena Viana Garcia

DOI: 10.47094/978-65-88958-41-4/201-213

CAPÍTULO 19

CRIAÇÃO DE UM APLICATIVO VOLTADO PARA UMA UNIDADE BÁSICA DE SAÚdE EM FORTALEZA

Isabella Araujo Duarte

Giovanna Rolim Pinheiro Lima

Idna Lara Goes de Sena

Laura Figueiredo Leite

Letícia Cavalcante Lócio

Livian Araújo Camelo Gomes

Maria Regina Cardoso Linhares Oliveira Lima

Maria Tereza Linhares Cardoso

Pedro Henrique Cardoso Nogueira

Rafael Albuquerque Franco

Rodrigo Carvalho Paiva

Berta Augusta Faraday Sousa Pinheiro

DOI: 10.47094/978-65-88958-41-4/214-229 
TELEMEDICINA E SUAS VARIÁVEIS NO CENÁRIO DE PANDEMIA MUNDIAL: UMA REVISÃO DE LITERATURA

Raniere Canteiro Garcia Lhamas

Andressa Marcolino Campos

Douglas Ferreira Lima

Gabriel Souza Ferreira Oliveira

Guilherme de Mendonça Lopes Beltrão

Luciana de Paula Santana

Nícollas Nunes Rabelo

DOI: 10.47094/978-65-88958-41-4/230-237

CAPÍTULO 21 238

MONITORIA ACADÊMICA NO ENSINO REMOTO: PERSPECTIVAS E DESAFIOS EM TEMPOS PANDÊMICOS

Felipe Gabriel Assunção Cruz

Givanildo Bezerra de Oliveira

Marcílio Delan Baliza Fernandes

Ana Lúcia Moreno Amor

DOI: 10.47094/978-65-88958-41-4/238-248

CAPÍTULO 22

A DOENÇA DO OLHO SECO NA SÍINDROME DE SJÖGREN

Bruna Rafaella Santos Torres

Carlos Eduardo Ximenes da Cunha

Carlos Henrique Bezerra de Siqueira

Flavia Emanuelly Alves França Gomes

Santília Tavares Ribeiro de Castro e Silva

Anna Caroline Guimarães Gomes

Laís Rytholz Castro

Dennis Cavalcanti Ribeiro Filho 
Lara Medeiros Pirauá de Brito

Marina Viegas Rezende Ribeiro

DOI: 10.47094/978-65-88958-41-4/249-259

CAPÍTULO 23 260

FEIRAAGROECOLÓGICA: DIFICULDADES E POTENCIALIDADES DE UM CIRCUITO CURTO DE COMERCIALIZAÇÃO

Maria Rita Garcia de Medeiros

Rônisson Thomas de Oliveira Silva

Maria Natalícia de Lima

Ana Beatriz Macêdo Venâncio dos Santos

DOI: 10.47094/978-65-88958-41-4/260-269

CAPÍTULO 24 270

AVALIAÇÃO DO IMPACTO DE UMA REDE SOCIAL EM USUÁRIOS DE UMA UNIDADE BÁSICA DE SAÚDE EM FORTALEZA

Luiz Gerson Gonçalves Neto

Letícia Cavalcante Lócio

Carlos Alexandre Leite Pereira Filho

Henrique Sousa Costa

Maria Helena dos Santos Macedo

Lígia Bringel Olinda Alencar

Berta Augusta Faraday Sousa Pinheiro

Isaac Dantas Sales Pimentel

DOI: 10.47094/978-65-88958-41-4/270-280 


\section{CAPÍTULO 2}

VACINAS CONTRA COVID-19: UMA BREVE DESCRIÇÃO POR MEIO DE REVISÃO INTEGRATIVA

\section{Fernanda Lima Marçal';}

Universidade Federal de Juiz de Fora - Campus Governador Valadares (UFJF-GV), Governador Valadares, Minas Gerais.

http://lattes.cnpq.br/1809994024341273

\section{Isabela Figueiredo e Souza;}

Universidade Federal de Juiz de Fora - Campus Governador Valadares (UFJF-GV), Governador Valadares, Minas Gerais.

http://lattes.cnpq.br/3569076802963408

\section{Maria Eduarda Coelho Gomes ${ }^{3}$;}

Universidade Federal de Juiz de Fora - Campus Governador Valadares (UFJF-GV), Governador Valadares, Minas Gerais.

http://lattes.cnpq.br/4972012821054625

\section{Larissa Lima Torres ${ }^{4}$;}

Universidade Federal de Juiz de Fora - Campus Governador Valadares (UFJF-GV), Governador Valadares, Minas Gerais.

http://lattes.cnpq.br/3303412979213025

\section{Isabela Campbell Santos;}

Universidade Federal de Juiz de Fora - Campus Governador Valadares (UFJF-GV), Governador Valadares, Minas Gerais.

http://lattes.cnpq.br/3590786832692185

\section{Thamara Lóren Lima ${ }^{6}$;}

Universidade Federal de Juiz de Fora - Campus Governador Valadares (UFJF-GV), Governador Valadares, Minas Gerais.

http://lattes.cnpq.br/4705584250713485

\section{Ludmilla Vieira Magalhães ${ }^{7}$;}

Universidade Federal de Juiz de Fora - Campus Governador Valadares (UFJF-GV), Governador Valadares, Minas Gerais.

http://lattes.cnpq.br/7331436221960780 


\section{Maria Eduarda Sirina Pereira ${ }^{8}$;}

Universidade Federal de Juiz de Fora - Campus Governador Valadares (UFJF-GV), Governador Valadares, Minas Gerais.

\section{http://lattes.cnpq.br/2223548422231907}

\section{Lucas Viana de Oliveira9;}

Universidade Federal de Juiz de Fora - Campus Governador Valadares (UFJF-GV), Governador Valadares, Minas Gerais.

\section{http://lattes.cnpq.br/8644562809376853}

\section{Larissa da Silva Torres França ${ }^{10}$;}

Universidade Federal de Juiz de Fora - Campus Governador Valadares (UFJF-GV), Governador Valadares, Minas Gerais.

http://lattes.cnpq.br/3099476534611190

\section{Natan Fiorotti da Silva ${ }^{11}$;}

Universidade Federal de Juiz de Fora - Campus Governador Valadares (UFJF-GV), Governador Valadares, Minas Gerais.

\section{http://lattes.cnpq.br/7077166783918572}

\section{Milena de Oliveira Simões ${ }^{12}$.}

Universidade Federal de Juiz de Fora - Campus Governador Valadares (UFJF-GV), Governador Valadares, Minas Gerais.

http://lattes.cnpq.br/6612444383939655

RESUMO: Introdução: A pandemia da COVID-19 representa um importante desafio de saúde pública mundial, sendo seu impacto sentido nas diversas esferas - biológica, social, econômica e cultural. A vacina, mais que uma fonte eficaz e segura de proteção contra doenças e infecções, representa atualmente a esperança pelo fim da pandemia e das medidas de isolamento e o consequente retorno às atividades econômicas. Objetivo: Apresentar, por meio de uma revisão integrativa, as características das principais vacinas produzidas contra COVID-19 atualmente, sendo elas CoronaVac (Sinovac), AstraZeneca (Universidade de Oxford), Pfizer (Pfizer e BioNTech) e Janssen (Johnson \& Johnson). Metodologia: Trata-se de uma revisão integrativa, realizada através de diferentes bases de dados. Dessa forma, compuseram este trabalho artigos e outras referências que abordaram a temática com o devido rigor científico. As vacinas foram apresentadas em tópicos individualizados. Resultados: Foram especificadas características dos imunizantes como princípio ativo, relação com as variantes, países que estão utilizando e os resultados atingidos com a imunização, bem como os efeitos colaterais e as razões pelas quais algumas vacinas estão com o seu uso suspenso. A relevância do presente estudo consistiu em reunir informações que, por vezes, se encontram fragmentadas e sem embasamentos científicos. Considerações finais: Estudos pautados na descrição das vacinas contra 
COVID-19 e fundamentados em evidências científicas são cruciais para combater a desinformação e apoiar o desenvolvimento de políticas públicas no enfrentamento da pandemia.

PALAVRAS-CHAVE: COVID-19. SARS-CoV-2. Prevenção.

\section{VACCINES AGAINST COVID-19: A BRIEF DESCRIPTION THROUGH INTEGRATIVE REVIEW}

ABSTRACT: Introduction: The COVID-19 pandemic represents an important public health challenge worldwide, and its impact is felt in different spheres - biological, social, economic and cultural. The vaccine, more than an effective and safe source of protection against diseases and infections, currently represents hope for the end of the pandemic and isolation measures and the consequent return to economic activities. Objective: To present, through an integrative review, the characteristics of the main vaccines produced against COVID-19 today, namely CoronaVac (Sinovac), AstraZeneca (Oxford University), Pfizer (Pfizer and BioNTech) and Janssen (Johnson \& Johnson). Methodology: This is an integrative review, carried out through different databases. Thus, this work was composed by articles and other references that approached the theme with due scientific rigor. Vaccines were presented on individual topics. Results: Characteristics of the immunizers were specified such as active ingredient, relationship with the variants, countries that are using and the results achieved with the immunization, as well as the side effects and the reasons why some vaccines are suspended. The relevance of this study was to gather information that is sometimes fragmented and without scientific basis. Final considerations: Studies based on the description of vaccines against COVID-19 and based on scientific evidence are crucial to combat disinformation and support the development of public policies to face the pandemic.

KEY-WORDS: COVID-19. SARS-CoV-2. Prevention.

\section{INTRODUÇÃO}

De acordo com a Organização Mundial de Saúde, a vacinação é uma maneira eficaz e segura de proteção contra doenças e infecções. Utilizada no mundo todo, essas fórmulas beneficiam-se das defesas naturais do corpo - por meio de formas inativas, antígenos não letais - estimuladas com o intuito de desenvolver uma resposta específica contra um dado patógeno ou agente etiológico (WHO, 2020). Sendo essa, a mais importante forma de assegurar a manutenção da saúde da população e sua proteção contra uma doença (FIOCRUZ, 2021a).

O Brasil apresenta um repertório de progressos na imunização gratuita. Para que tais avanços surgissem, critérios de eficiência, segurança e epidemiológicos foram considerados, além da adesão de imunizantes pelo Comitê Técnico Assessor de Imunizações e posterior análise pela Comissão Nacional de Incorporação de Tecnologias no SUS. Para a COVID-19 não foi diferente (CONITEC, 2021). 
Os imunizantes utilizados para combatê-la possuem o propósito de reduzir o número de pessoas com sintomas, internações, casos graves e óbitos. Com o tempo, espera-se também reduzir a circulação do vírus SARS-CoV-2 (FIOCRUZ, 2021b).

Quatro importantes tipos de vacinas ganham destaque, sendo um deles aquelas que utilizam do próprio vírus, enfraquecido ou inativo, capazes de fomentar a elaboração de uma resposta imune, sem risco de letalidade. Outro tipo, são as de origem genética. Essas fazem uso de DNA ou RNA, de forma que o corpo sintetize cópias de alguma proteína do vírus, induzindo a imunoproteção. Além disso, ainda existem as vacinas do tipo vetor viral, que utilizam, por sua vez, outro vírus, geneticamente alterado, para produzir, no indivíduo, as proteínas virais que induzirão a resposta imunológica. E por fim, as vacinas à base de proteínas, as quais empregam uma proteína - ou parte dela - que seja ou imite a proteína do vírus para a estimulação do sistema das células de defesa humana, os leucócitos (MÉDICOS SEM FRONTEIRAS, 2020).

Com isso, podemos elencar as duas principais vacinas utilizadas no Brasil até o momento. A AstraZeneca é uma fórmula do tipo vetor viral, resumindo-se em um vírus defeituoso/enfraquecido sem potencial de multiplicação com uma pequena porção do genoma referido. Diferentemente, a CoronaVac é constituída pelo vírus da SARS-CoV-2 inativado de estrutura completa, também incapaz de multiplicação. Ambas conseguem provocar uma resposta que proporcionará os fatores de proteção importantes contra a infecção (SECRETARIA DE SAÚDE DO ESTADO DO CEARÁ, 2021).

Dessa forma, o objetivo do presente estudo consiste em realizar uma revisão integrativa acerca das principais vacinas existentes contra a COVID-19, sendo elas: Coronavac (Sinovac), AstraZeneca (Universidade de Oxford), Pfizer (Pfizer e BioNTech) e Janssen (Johnson \& Johnson). Busca-se elencar o princípio ativo, a eficácia, a relação das vacinas com as variantes, os países que estão utilizando e os resultados obtidos com a imunização, bem como os efeitos colaterais e as razões pelas quais a utilização de algumas vacinas está sendo suspensa.

\section{METODOLOGIA}

Trata-se de uma revisão integrativa, cuja pesquisa bibliográfica se concentrou em bancos de dados como o Pubmed e sites de órgãos públicos internacionais e nacionais, como a Organização Mundial da Saúde (ONU) e Fundação Oswaldo Cruz (FIOCRUZ), respectivamente.

\section{RESULTADOS E DISCUSSÕES}

Os tópicos abaixo especificam características dos imunizantes CoronaVac da Sinovac, AstraZeneca da Universidade de Oxford, Pfizer da Pfizer/BioNTech e Janssen da Johnson \& Johnson, relacionadas ao princípio ativo, eficácia, países de uso ativo e resultados obtidos com a imunização, bem como, efeitos colaterais e as razões pelas quais a utilização de algumas vacinas está sendo suspensa. 


\section{CoronaVac}

A vacina CoronaVac foi desenvolvida pelo laboratório chinês Sinovac. Trata-se de uma vacina composta por vetores virais inativados e administrada em duas doses para efetivo desenvolvimento da resposta imunológica (LIMA; ALMEIDA; KFOURI, 2021).

Conforme dados de um estudo recente (BARANIUK, 2021), a vacina chinesa CoronaVac foi aprovada para uso emergencial em mais de 30 países, incluindo Bahrein, Guiana, Hungria, Sérvia e Emirados Árabes Unidos. Contudo, devido à opacidade em torno dos dados e diversos acordos políticos e econômicos, no momento, esta vem sendo utilizada apenas pelo Brasil, Chile, Indonésia, Laos, México e Turquia, além de seu país de origem, a China.

Em uma pesquisa realizada com profissionais da saúde da Turquia, para identificar efeitos colaterais da vacina (RIAD et al., 2021), constatou que a CoronaVac obteve eficácia inicial de 91,25\% em estudo de fase III, contra casos graves da doença, e apresentou os seguintes efeitos colaterais: dor no local da injeção $(41,5 \%)$, fadiga $(23,6 \%)$, dor de cabeça $(18,7 \%)$, dor muscular $(11,2 \%)$ e dores nas articulações (5,9\%). As mulheres (67,9\%) foram mais afetadas por efeitos colaterais do que os homens $(51,4 \%)$. Também foram relatadas pelos participantes, reações adversas incomuns como febre $(0,1 \%-1 \%)$ e erupções cutâneas $(1,5 \%)$. Outras reações adversas relacionadas à pele como rubor, urticária e acne ocorreram em $0,1,0,8 \%$ e $0,1 \%$ respectivamente. A hiposmia foi uma reação adversa "rara" $(<0,01 \%)$, podendo estar relacionada aos distúrbios do paladar relatados por 0,9\%, embora sejam efeitos colaterais não esperados (RIAD et al., 2021).

De acordo com a pesquisa financiada pela organização Pan Americana de Saúde, Fundação Oswaldo Cruz (FIOCRUZ) e Secretaria Municipal de Saúde de Manaus, a administração de pelo menos uma dose de CoronaVac mostrou eficácia também contra a infecção sintomática de SARSCoV-2 no cenário de transmissão da variação epidêmica P.1 (HITCHINGS et al., 2021).

Vale ressaltar que, segundo Santos (2021), numa publicação ao site Marco Zero, o mecanismo de ação da CoronaVac, em tese, seria melhor ou mais provável em conseguir responder às variantes esparsas que surgem na pandemia. Tal feito se daria devido ao emprego do material da superfície do vírus inativado, que agrupa proteínas "S", "M" e "E”, aumentando o número de pontos em que a vacina poderia agir, caso um outro sofra uma mutação considerável.

Mesmo com as divergências e disputas políticas que ocorreram durante a pandemia em torno das diretrizes de vacinação (GRAMACHO; TURGEON, 2020), a CoronaVac é uma das vacinas que vem sendo aplicadas atualmente no Brasil para o combate da pandemia, e mais, sendo desenvolvida em parceria com o Instituto Butantan na cidade de São Paulo (INSTITUTO BUTANTAN, 2021). 
A vacina AstraZeneca (ChAdOx nCoV-19 - AZD1222) da Universidade de Oxford, funciona através de um vetor viral de um adenovírus de chimpanzés. Vacinas com esse mecanismo utilizam vírus deficientes em replicação projetados para expressar a sequência genética do antígeno de interesse - no caso, o adenovírus de chimpanzé com a proteína S do SARS-CoV-2, nas células hospedeiras gerando assim a resposta imune no organismo contra o antígeno (CREECH; WALKER; SAMUELS, 2021).

Knoll e Wonodi (2021) publicaram em uma revista conceituada no meio científico sobre a eficácia da vacina AstraZeneca. Os estudos foram conduzidos no Reino Unido, Brasil e África do Sul em adultos com 18 anos ou mais. Depois da fase I, os resultados guiaram a aplicação de duas doses com 28 dias de intervalo. Os resultados da eficácia se basearam nos resultados das populações do Brasil e do Reino Unido e contaram com 11.636 participantes, majoritariamente entre 18 e 55 anos $(87,8 \%)$, com quatro meses de acompanhamento. Entre o grupo intervenção $(n=5807)$ não houve internação hospitalar relacionada à COVID-19, já no grupo controle ( $\mathrm{n}=5829)$ houve 10 internações e, dentre elas, duas classificadas como severas. A eficácia da vacina contra o desfecho primário de COVID-19 foi de 70,4\%, ocorrendo a partir do $14^{\circ}$ dia após a segunda dose. Quando avaliada a eficácia a partir do $21^{\circ}$ dia após a primeira dose, o resultado foi semelhante aos anteriores, sugerindo existência de proteção a curto prazo com apenas uma dose. Os autores ressaltaram a necessidade de realização de mais estudos para avaliação da eficácia da vacina contra a infecção assintomática, já que, apesar de ser constatada em 58,9\%, o número de assintomáticos foi baixo, 69 casos dentre 6.638 participantes. Além disso, entre os resultados, apenas 12,1\% dos participantes (1.418) possuíam mais de 55 anos, necessitando também de mais estudos com essa população, principalmente por possuirem maiores riscos de desfechos graves na infecção pelo SARS-CoV-2 (KNOLL; WONODI, 2021).

Atualmente, a vacina AstraZeneca está aprovada para uso nos países membros da iniciativa COVAX (195 países, incluindo Brasil), bem como na Índia, Reino Unido e México (CREECH; WALKER; SAMUELS, 2021).

A respeito dos seus efeitos colaterais, a vacina AstraZeneca foi suspensa por um curto período após relatos de formação de coágulos em alguns participantes. No entanto, chegou-se à conclusão de que a formação de coágulos é um efeito colateral extremamente raro da vacina, sendo os benefícios superiores aos riscos. E ainda, não encontrando nenhuma ligação definitiva entre a vacina e os coágulos. De acordo com a literatura, uma explicação possível para a formação desses coágulos seria uma condição semelhante à trombocitopenia induzida por heparina - uma reação à heparina, a qual é um anticoagulante usado para prevenir a formação de coágulos sanguíneos. Em casos muito raros, o tratamento pode levar à diminuição das plaquetas no sangue (trombocitopenia) e coágulos (MAHASE, 2021).

Mediante casos de trombose, a Agência Europeia de Medicamentos iniciou uma investigação para analisar possível associação com a vacina Oxford/AstraZeneca e seu nível de segurança. Foram estudados 62 casos de trombose do seio venoso e 24 casos de trombose da veia esplâncnica até a data de 22 de março de 2021, destes 18 casos fatais. No momento da investigação, cerca de 25 milhões 
de pessoas da União Europeia e Reino Unido teriam recebido esse imunizante. Como resultado, a Agência confirmou a segurança da vacina e atestou que majoritariamente os casos aconteceram em mulheres de até 60 anos dentro das duas primeiras semanas de vacinação (MAHASE, 2021).

Assim, contextualizando o risco de coágulos com a vacina AstraZeneca: 1 a cada 1000 pessoas por ano desenvolverá um coágulo sanguíneo em viagens aéreas; 1 a cada 2.000 mulheres a cada ano desenvolverá um coágulo sanguíneo ao tomar a pílula anticoncepcional oral combinada; e 1 a cada 250.000 pessoas vacinadas com a vacina AstraZeneca desenvolverá coágulos sanguíneos com plaquetas em baixas dosagens (MAHASE, 2021).

\section{Pfizer}

A vacina da Pfizer (BNT162b2), laboratório Pfizer/BioNTech, tem como princípio ativo um RNA mensageiro modificado com nucleosídeo (modRNA) expresso em nanopartículas lipídicas. Assim, codifica a proteína spike (S) para o vírus SARS-CoV-2, sendo o principal local para anticorpos neutralizantes (PADDA; PARMAR, 2021; POLACK et al., 2020). Em relação à sua eficácia, duas doses da Pfizer (BNT162b2) foram capazes de conferir 95\% de proteção contra COVID-19 em indivíduos com idade entre 16 anos ou mais. Além disso, a segurança ao longo de dois meses foi próxima à de outras vacinas virais (POLACK et al., 2020).

Atualmente a vacina Pfizer (BNT162b2) está sendo utilizada em cerca de 90 países, dentre eles, países europeus como França, Alemanha, Itália, Portugal, Espanha e Reino Unido e outros como Israel, Japão, Chile e Peru (RITCHIE et al., 2021).

Resultados de uma análise de 927 casos de COVID-19 sintomáticos confirmados foram observados em um estudo de Fase III até 13 de março de 2021. Esse estudo evidenciou que a vacina Pfizer (BNT162b2) teve uma eficácia de 91,3\% contra a COVID-19, sendo medida de sete dias até seis meses após a segunda dose. Já em relação a casos graves da doença, a vacina foi 100\% eficaz, como definido pelos Centros de Controle e Prevenção de Doenças (CDC) dos EUA, e 95,3\% eficaz, segundo a Food and Drug Administration (FDA) dos EUA (PFIZER, 2021).

Os principais efeitos colaterais da Pfizer (BNT162b2) foram caracterizados por fadiga, dor de cabeça e dor leve à moderada de curto prazo no local da injeção (POLACK et al., 2020). Entretanto, outros sintomas também foram descritos, sendo eles: edema no local da injeção (10,5\%), vermelhidão no local da injeção $(9,5 \%)$, febre $(14,2 \%)$, dor muscular $(38,3 \%)$, calafrios $(31,9 \%)$, dor nas articulações $(23,6 \%)$, náusea $(1,1 \%)$, mal-estar $(0,5 \%)$, reação alérgica grave (rara) e inclinação facial temporária de um lado (raro) (PADDA; PARMAR, 2021).

Ademais, durante os ensaios clínicos foram relatados quatro eventos adversos graves, porém raros, relacionados à vacinação com a Pfizer (BNT162b2), dentre eles a linfadenopatia axilar direita, parestesia do membro inferior direito, arritmia ventricular paroxística e lesão no ombro associada à injeção da vacina (PADDA; PARMAR, 2021). 
Aprovada em fevereiro de 2021, a vacina da Janssen, chamada de ENSEMBLE, é baseada em vetores de adenovírus sorotipo 26 (Ad26), vírus que causam o resfriado comum. Uma outra parte da vacina envolve o código genético do próprio SARS-CoV-2, que possui externamente uma coroa em sua superfície, formada pelos chamados "spikes" que são responsáveis pela ligação do vírus às células do corpo humano. Dessa forma, para a produção da vacina, um pedaço da proteína "S" é colocado dentro do adenovírus, sendo este o vetor ou transportador (JANSSEN, 2021).

A vacina Janssen COVID-19 é administrada por via intramuscular em dose única de 0,5 mL, sendo incolor a levemente amarelada. Cada frasco da vacina contém cinco doses. Sua formulação não contém conservantes, de modo que depois que a primeira dose for retirada, sua validade é de até seis horas com o frasco mantido entre $2^{\circ} \mathrm{a} 8^{\circ} \mathrm{C}$ ou até duas horas em sala com temperatura máxima de $25^{\circ} \mathrm{C}$ (JANSSEN, 2021).

Ensaio clínico de fase III, randomizado, duplo-cego e controlado, incluiu 19.630 indivíduos adultos negativos para SARS-CoV-2 que receberam a vacina Janssen (Ad26.COV2.S) e 19.691 que receberam placebo. Os desfechos primários contemplaram uma eficácia de 66,9\% em prevenir casos moderados e graves de COVID-19 com 14 dias após a administração e de 66,1\% após 28 dias. A eficácia da vacina foi maior contra COVID-19 grave, sendo de 76,7\% após 14 dias e de 85,4\% após 28 dias. Em relação aos efeitos adversos, no grupo intervenção, a dor no local da injeção foi a reação local mais comum (em 48,6\% dos participantes); as reações sistêmicas mais comuns foram cefaleia (em 38,9\%), fadiga (em 38,2\%), mialgia (em 33,2\%) e náuseas (em 14,2\%). Foram observados eventos tromboembólicos venosos, convulsão e zumbido, cuja relação causal não pôde ser associada à vacina (SADOFF, 2021).

Apenas a União Europeia, Canadá e Reino Unido estão utilizando a Janssen em suas populações. No Brasil, o Plano Nacional de Operacionalização de Vacinação contra a COVID-19 citava a expectativa de obter 38 milhões de doses dessa vacina a partir do segundo trimestre, no entanto nenhuma compra foi de fato efetivada (JANSSEN, 2021).

\section{Vacinas e as novas variantes do vírus}

As mudanças genéticas que ocorrem à medida que um vírus faz novas cópias de si mesmo, são denominadas mutações. O surgimento de mutações é um evento natural e esperado dentro do processo evolutivo dos vírus, em especial daqueles que possuem RNA como material genético, tal como o SARS-CoV-2 (BRASIL, 2021b; OPAS/OMS, 2021). É a partir dos processos de mutação e de pressões de seleção que são geradas variantes, ou seja, novas configurações do mesmo vírus, caracterizadas por carregarem alterações em seu material genético em relação ao "vírus original".

Em relação ao SARS-CoV-2, até o momento, foram identificadas quatro variantes classificadas como variantes de atenção e/ou preocupação (VOC, do inglês "variant of concern"), de acordo com a OMS. Significando, variantes que apresentam mutações que ocasionam relevantes alterações clínicoepidemiológicas, como maior gravidade e superior potencial de infectividade (BRASIL, 2021b; OPAS/ 
OMS, 2021; WHO, 2021). Além das variantes VOC, a OMS forneceu uma definição operacional para outras variantes, denominadas variantes de interesse (VOI, do inglês "variant of interest"), as quais são caracterizadas por apresentarem alterações estruturais (fenotípicas) - em comparação a um grupo de referência - e capacidade para causar transmissão comunitária/múltiplos casos/conglomerados de casos de COVID-19 ou terem sido detectadas em diversos países (OPAS/OMS, 2021).

Vale ressaltar que a VOI da linhagem B.1.617, identificada primeiramente na Índia, em amostras de outubro de 2020, trata-se da variante que recebeu da OMS, a mais recente designação de variante VOC, devido ao potencial de relevantes mutações e pelo fato de estar sendo identificada globalmente. A VOC B.1.617 foi notificada, até então, em 49 países, porém ainda não há, no Brasil, casos da COVID-19 por essa variante confirmados oficialmente e encaminhados ao Ministério da Saúde (MS) (BRASIL, 2021a).

Dado o cenário pandêmico e o preocupante surgimento de novas mutações do SARS-CoV-2, foi instituído, no Brasil, um monitoramento, de âmbito nacional, das variantes VOC. Nesse contexto, a Secretaria de Vigilância em Saúde (SVS), do MS, realiza levantamentos semanais, com as Secretarias de Saúde de cada Unidade Federada (UF), acerca de resultados dos sequenciamentos genômicos realizados, informados pela rede laboratorial de referência (BRASIL, 2021a). Nesse âmbito, até então, no Brasil, foram identificadas três variantes de atenção e/ou preocupação (VOC) que estão sob vigilância em outros países: a VOC B.1.1.7 (ou VOC 202012/01 ou 20I/501Y.V1), a VOC B.1.351 (ou VOC 202012/02 ou 20H/501Y.V2) e a VOC B.1.1.28.1 (ou P.1 ou 20J/501Y.V3). Além disso, também foi identificada uma variante de interesse (VOI): a B.1.1.28.2 (ou P.2 ou 20B/S.484K) (BRASIL, 2021a; OPAS/OMS, 2021).

No que diz respeito às vacinas, de modo geral, os estudos in vitro realizados com a variante VOC 202012/01, por exemplo, embora apresentem limitações intrínsecas - seja pela metodologia ou pelo tamanho de amostra, seja por considerarem apenas o braço humoral da resposta imune indicaram que a eficácia das vacinas que estão sendo administradas é semelhante ou moderadamente menor, acarretando nenhum ou quase nenhum impacto no processo de imunização vigente (GÓMEZ; PERDIGUEIRO; ESTEBAN, 2021). A tabela 1 resume os principais aspectos, segundo a WHO (2021), referentes às variantes emergentes do SARS-CoV-2, detectadas até o momento no Brasil. 


\begin{tabular}{|c|c|c|c|}
\hline Variante - identificação & $\begin{array}{l}\text { VOC 202012/01 ou } \\
\text { 20I/501Y.V1 }\end{array}$ & $\begin{array}{c}\text { VOC } 202012 / 02 \text { ou } \\
20 H / 501 Y . V 2\end{array}$ & $\begin{array}{l}\text { VOC 202101/02 ou } \\
\text { 20J/501Y.V3 ou P.1 }\end{array}$ \\
\hline Linhagem & B.1.1.7 & B.1.351 & B.1.1.28.1 \\
\hline $\begin{array}{c}\text { Detectado pela primeira } \\
\text { vez por }\end{array}$ & Reino Unido & África do Sul & Brasil / Japão \\
\hline Amostra(s) mais antiga(s) & 20 de setembro de 2020 & Início de agosto de 2020 & Dezembro de 2020 \\
\hline $\begin{array}{l}\text { Principais mutações } \\
\text { referentes à proteína Spike }\end{array}$ & $\begin{array}{c}\text { Deleção H69 / V70; } \\
\text { eliminação Y144; N501Y; } \\
\text { A570D e P681H }\end{array}$ & $\begin{array}{c}\text { Deleção L242 / A243 / L244; } \\
\text { K417N; E484K e N501Y }\end{array}$ & $\begin{array}{l}\text { K417T; E484K e } \\
\text { N501Y }\end{array}$ \\
\hline Mutação comum & \multicolumn{3}{|c|}{ Deleção S106 / G107 / F108 na proteína não estrutural 6 (nsp6) } \\
\hline Transmissibilidade & $\begin{array}{c}\text { Aumentada (43\%-90\%); } \\
\text { aumento da taxa de ataque } \\
\text { secundário [11\% (IC 95\%: } \\
\text { 10,9-11,2\%)] entre os } \\
\text { contatos mais próximos }\end{array}$ & $\begin{array}{c}\text { Aumentada [1,50 (IC 95\%: } \\
\text { 1,20-2,13) vezes mais } \\
\text { transmissível do que a } \\
\text { variante circulante anterior] }\end{array}$ & $\begin{array}{l}\text { Aumentada; mais } \\
\text { transmissível do que } \\
\text { a variante circulante } \\
\text { anterior }\end{array}$ \\
\hline Gravidade & $\begin{array}{l}\text { Possível aumento do } \\
\text { risco de hospitalização, } \\
\text { gravidade e mortalidade. } \\
\text { Outros estudos mostram } \\
\text { impacto limitado/misto }\end{array}$ & $\begin{array}{c}\text { Possível aumento em } 20 \% \\
\text { do risco de mortalidade } \\
\text { hospitalar }\end{array}$ & $\begin{array}{l}\text { Sob investigação; } \\
\text { impacto limitado }\end{array}$ \\
\hline $\begin{array}{l}\text { Avaliação de potencial } \\
\text { reinfecção/descoberta }\end{array}$ & $\begin{array}{l}\text { Ligeira redução em } \\
\text { capacidade de } \\
\text { neutralização, mas os } \\
\text { títulos neutralizantes gerais } \\
\text { ainda permaneceram acima } \\
\text { dos níveis esperados para } \\
\text { conferir proteção }\end{array}$ & $\begin{array}{l}\text { Capacidade de neutralização } \\
\text { diminuída, sugerindo risco } \\
\text { potencial aumentado de } \\
\text { reinfecção }\end{array}$ & $\begin{array}{c}\text { Capacidade de } \\
\text { neutralização } \\
\text { diminuída; reinfecções } \\
\text { relatadas }\end{array}$ \\
\hline
\end{tabular}




\begin{tabular}{|c|c|c|c|}
\hline $\begin{array}{c}\text { Potenciais impactos em } \\
\text { vacinas }\end{array}$ & 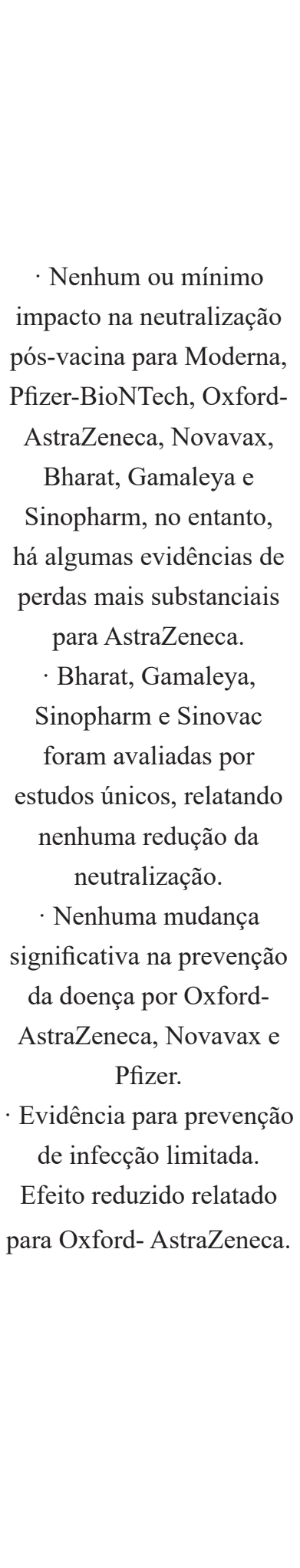 & 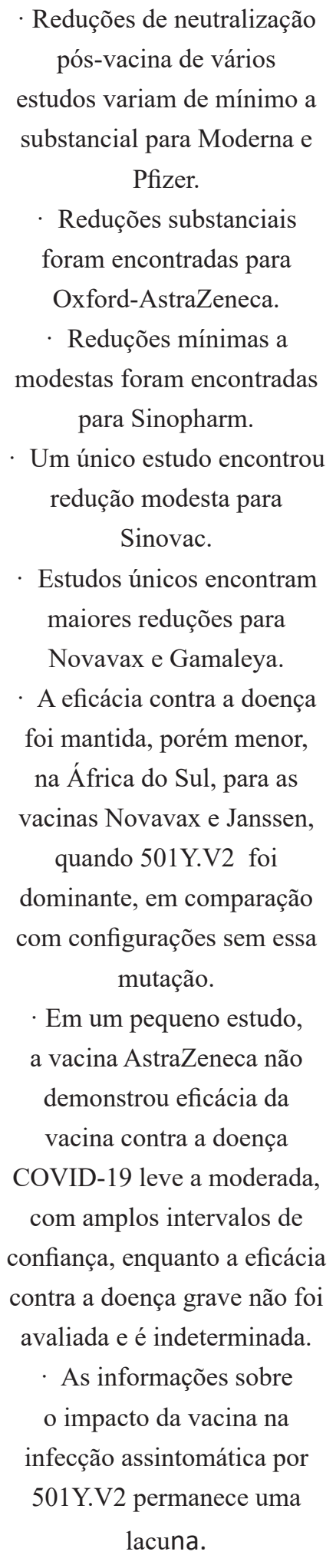 & $\begin{array}{c}\text { · Redução de } \\
\text { neutralização limitada } \\
\text { em teste pós-vacina por } \\
\text { Oxford-AstraZenec, } \\
\text { Moderna e Vacinas } \\
\text { Pfizer; contudo há } \\
\text { alguma evidência } \\
\text { de redução mais } \\
\text { substancial. } \\
\text { · Sugestão preliminar } \\
\text { de perda de } \\
\text { neutralização após } \\
\text { a vacinação com } \\
\text { Sinovac. } \\
\text { Eficácia preliminar da } \\
\text { vacina Sinovac para P.1 } \\
\text { foi estimada no Brasil. }\end{array}$ \\
\hline $\begin{array}{c}\text { Potenciais impactos em } \\
\text { diagnósticos }\end{array}$ & $\begin{array}{l}\text { Falha no alvo do gene } \mathrm{S} \\
\text { (SGTF). Nenhum impacto } \\
\text { sobre Ag RDTs observado }\end{array}$ & $\begin{array}{l}\text { Nenhum relatado até o } \\
\text { momento }\end{array}$ & $\begin{array}{c}\text { Nenhum relatado até o } \\
\text { momento }\end{array}$ \\
\hline
\end{tabular}

Fonte: Adaptado de WHO (2021), tradução dos autores. 
Segundo o boletim epidemiológico especial (elaborado pela SVS, do MS), referente à semana epidemiológica 19, de 2021, foram observados 3.520 registros de casos da COVID-19 pelas variantes VOC, identificados em 25 UF do Brasil, sendo três casos da VOC B.1.351 - da África do Sul, identificados, recentemente, em município do interior do estado de São Paulo, 113 da VOC B.1.1.7 do Reino Unido, detectada em 12 UF do país e 3.404 da VOC P.1 - do Amazonas (BRASIL, 2021a).

Juntos, esses resultados confirmam que é imperativo minimizar a circulação do vírus, prevenir infecções e reduzir as oportunidades de evolução do SARS-CoV-2 - que podem levar a mutações e, por conseguinte, à redução da eficácia das vacinas existentes. É importante frisar que somente através da compreensão detalhada da estrutura do vírus, da biologia e do desenvolvimento de vacinas será possível, então, alcançar o controle das infecções ocasionadas pelo SARS-CoV-2 (GÓMEZ; PERDIGUEIRO; ESTEBAN, 2021).

Por fim, torna-se relevante destacar que, mais investigações epidemiológicas e virológicas estão sendo realizadas, visando à continuidade da avaliação da transmissibilidade, gravidade, risco de reinfecção e resposta de anticorpos a essas novas variantes. Tais investigações se expandem, inclusive, para o campo da análise do potencial impacto nas medidas de saúde pública, incluindo diagnóstico, tratamento e vacinas (OPAS/OMS, 2021), demonstrando assim, a dinamicidade científica e a sua contribuição direta para o bem-estar e para a saúde da população.

\section{CONCLUSÃO}

As vacinas são formas de imunização, com diferentes mecanismos de ação, as quais necessitam de rigorosas etapas de produção. Constituem, ainda, o modo mais relevante de garantir maior preservação da saúde e defesa contra uma doença infectocontagiosa. Assim, no contexto de urgência da pandemia de COVID-19, as vacinas desenvolvidas tiveram algumas de suas etapas de produção aceleradas, mas todas realizadas. No Brasil, até o momento, as vacinas utilizadas contra a doença são as de mecanismo do tipo vetor viral e do tipo vírus inativado de estrutura completa. Destas, no presente estudo foram elencadas: CoronaVac, AstraZeneca, Pfizer e Janssen; relacionando características e especificidades no desenvolvimento, comercialização e utilização.

Os dados expostos evidenciam o rigor científico do processo de elaboração de vacinas e os desafios aos quais estamos imersos na conjuntura pandêmica atual, principalmente diante do cenário de novas mutações do vírus e suas nuances. Dessa forma, essas contribuições apontam para a importância da evidência científica não apenas no contexto das vacinas contra a COVID-19 como também em toda análise epidemiológica da pandemia.

\section{DECLARAÇÃO DE INTERESSES}

Nós, autores deste artigo, declaramos que não possuímos conflitos de interesses de ordem financeira, comercial, política, acadêmica ou pessoal. 


\section{REFERÊNCIAS}

BARANIUK, Chris. What do we know about China's covid-19 vaccines? BMJ 373, n912, 09 Abr 2021. Disponível em: <https://www.bmj.com/content/373/bmj.n912>. Acesso em: 21 de Abr 2021.

BRASIL. Ministério da Saúde. Secretaria de Vigilância em Saúde. Boletim Epidemiológico Especial: Doença pelo Coronavírus COVID-19. Semana Epidemiológica 19 (9/5 a 15/5/2021) de 2021. Brasília: Ministério da Saúde/Secretaria de Vigilância em Saúde, 2021a. Disponível em: <https:/www.gov.br/ saude/pt-br/media/pdf/2021/maio/21/boletim_epidemiologico_covid_63_final_21maio.pdf $>$. Acesso em 22 mai. 2021.

BRASIL. Ministério da Saúde. Secretaria de Vigilância em Saúde. Nota Técnica nº 127/2021-CGPNI/ DEIDT/SVS/MS. Recomendações quanto à nova variante do SARS-CoV-2 no Brasil. Brasília: Ministério da Saúde/Secretaria de Vigilância em Saúde, 2021b. Disponível em: <https:/www.gov.br/ saude/pt-br/media/pdf/2021/fevereiro/02-1/nota-tecnica-recomendacoes-quanto-a-nova-variante-dosars-cov-2-no-brasi.pdf>. Acesso em: 20 abr. 2021.

CREECH, C. Buddy; WALKER, Shannon C.; SAMUELS, Robert J. SARS-CoV-2 Vaccines. Jama, [S.L.], v. 325, n. 13, p. 1318, 6 abr. 2021. American Medical Association (AMA). http:// dx.doi.org/10.1001/jama.2021.3199. Disponível em: https://jamanetwork.com/journals/jama/ fullarticle/2777059. Acesso em: 20 abr. 2021.

Comissão Nacional de Incorporação de Tecnologias no Sistema Único de Saúde - CONITEC. A comissão. 2021. Disponível em: <http://conitec.gov.br/entenda-a-conitec-2 > Acesso em: 22 mai. 2021.

FIOCRUZ. Por que o contato direto com o vírus não gera imunidade para aqueles que já contraíram a Covid-19? 2021a. Disponível em: < https://portal.fiocruz.br/pergunta/por-que-o-contato-direto-como-virus-nao-gera-imu nidade-para-aqueles-que-ja-contrairam-0>. Acesso em: 19 abr. 2021.

FIOCRUZ. Qual a importância da vacinação contra a Covid-19?, 2021b. Disponível em: <https:// portal.fiocruz.br/busca?search_api_views_fulltext=vacina\%20covid $>$.Acesso em: 19 abr. 2021.

GÓMEZ, Carmen Elena; PERDIGUERO, Beatriz; ESTEBAN, Mariano. Emerging SARS-CoV-2 Variants and Impact in Global Vaccination Programs against SARS-CoV-2/COVID-19. Vaccines, [S. 1.], v. 9, n. 3, p. 243, 2021. Disponível em: <https://www.mdpi.com/2076-393X/9/3/243>. Acesso em: 19 abr. 2021.

GRAMACHO, Wladimir G.; TURGEON, Mathieu. When politics collides with public health: COVID-19 vaccine country of origin and vaccination acceptance in Brazil. Vaccine, 06 Abr 2021. Disponível em: <https://doi.org/10.1016/j.vaccine.2021.03.080>. Acesso em: 21 de Abr 2021.

HITCHINGS, Matt D.T; et al.Effectiveness of CoronaVac in the setting of high SARS-CoV-2 P.1 variant transmission in Brazil: A test-negative case-control study. MedRxiv, the preprint server for health science, Abril 2021. 
Disponível em: <https:/www.medrxiv.org/content/10.1101/2021.04.07.21255081v1>. Acesso em: 21 de Abr 2021.

INSTITUTO BUTANTAN. Autorização temporária de uso emergencial da vacina adsorvida covid-19 (inativada), 2021. Disponível em: $<$ https://vacinacovid.butantan.gov.br/index $>$. Acesso em: 21 de Abr 2021.

JANSSEN PHARMACEUTICAL COMPANIES. Emergency use authorization (eua) of the janssen covid-19 vaccine to prevent coronavirus disease 2019 (covid-19). Revised: Mar/19/2021 (C) 2021. Disponível em: <https://www.janssenlabels.com/emergency-use-authorization/Janssen+COVID19+Vaccine-HCP-fact-sheet.pdf>. Acesso em: 20 abril 2020.

KNOLL, Maria Deloria; WONODI, Chizoba. Oxford-AstraZeneca COVID-19 vaccine efficacy. The Lancet, [S.L.], v. 397, n. 10269, p. 72-74, jan. 2021. Elsevier BV. http://dx.doi. org/10.1016/s0140-6736(20)32623-4. Disponível em: <https://www.thelancet.com/journals/ lancet/article/PIIS0140-6736(20)32623-4/fulltext?fbclid=IwAR2zWTx86uAi8IhL5Vy_ CBMs7y1xQ33ODsVeym3FVtUKdJXBx5dSJH7g6K0>. Acesso em: 20 abr. 2021.

LIMA, Eduardo Jorge da Fonseca; ALMEIDA, Amalia Mapurunga; KFOURI, Renato de Ávila. Vacinas para COVID-19 - o estado da arte. Revista Brasileira Saúde Materno Infantil, vol.21 supl.1 Recife Feb. 2021 Epub Feb 24, 2021. Disponível em: <https://www.scielo.br/scielo.php?pid=S151938292021000100013\&script=sci_arttext\&tlng=pt $>$. Acesso em: 20 Abr 2021.

MAHASE, Elisabeth. AstraZeneca vaccine: blood clots are "extremely rare" and benefits outweigh risks, regulators conclude. Bmj, [S.L.], p. 931, 8 abr. 2021. BMJ. http://dx.doi.org/10.1136/bmj.n931. Disponível em: <https://www.bmj.com/content/373/bmj.n931.short>. Acesso em: 20 abr. 2021.

MÉDICOS SEM FRONTEIRAS. Desafios da vacina: entenda as principais etapas para o desenvolvimento das vacinas, como as da Covid-19. 2020. Disponível em:

$<$ https://coronavirus.msf.org.br/desafios-da-vacina/?gclid=Cj0KCQjwse-DBhC7ARIsAI8YcWJsB 3TX1YNIlcVj95L132Qfmh59pKGC-p9KRBonn3wcBcuKMz_KoH0aAqRjEALw_wcB>. Acesso em: 18 abr. 2021.

OPAS/OMS. Atualização Epidemiológica: Variantes de SARS-CoV-2 nas Américas. 24 de março de 2021. Washington: OPAS/OMS, 2021. Disponível em: <https://iris.paho.org/handle/10665.2/53376>. Acesso em: 20 abr. 2021.

PADDA, Inderbir S.; PARMAR, Mayur. COVID (SARS-COV-2) Vaccine. StatPearls Publishing, Treasure Island (FL) fev. 2021. Disponível em: <https://www.ncbi.nlm.nih.gov/books/ NBK567793/\#!po=3.57143>. Acesso em: 15 abr. 2021.

PFIZER. Pfizer and biontech confirm high efficacy and no serious safety concerns through up to six months following second dose in updated topline analysis of landmark covid-19 vaccine study. April, 2021. Disponível em: <https:/www.pfizer.com/news/press-release/press-release-detail/pfizer-andbiontech-confirm-high-efficacy-and-no-serious>. Acesso em: 17 abr. 2021. 
POLACK, Fernando P.; THOMAS, Stephen J; KITCHIN, Nicholas; ABSALON, Judith; GURTMAN, Alejandra; LOCKHART, Stephen; PEREZ, John L.; MARC, Gonzalo Pérez; MOREIRA, Edson D.; ZERBINI, Cristiano; BAILEY, Ruth; SWANSON, Kena A. Safety and Efficacy of the BNT162b2 mRNA Covid-19 Vaccine. New England Journal of Medicine, 383, n. 27, p. 2603-2615, 31 dez. 2020. Disponível em: https://www.nejm.org/doi/full/10.1056/nejmoa2034577. Acesso em: 18 abr. 2021.

RIAD, Abanoub; et al. Prevalence and risk factors of CoronaVac side effects: an independent crosssectional study among healthcare workers in Turkey. Masaryk, Faculdade de medicina, 2021. Disponível em: <https://papers.ssrn.com/sol3/papers.cfm?abstract_id=3820571>. Acesso em: 21 de Abr 2021.

RITCHIE, Hannah; ORTIZ-OSPINA, Esteban; BELTEKIAN, Diana; MATHIEU, Edouard; HASELL, Joe; MACDONALD, Bobbie; GIATTINO, Charlie; APPEL, Cameron; ROSER, Max; VAN WOERDEN, Ernst; GAVRILOV, Daniel; BERGEL, Matthieu Bergel; CRAWFORD, Jason; GERBER, Marcel. Coronavirus (COVID-19) Vaccinations. Source information country by country. Our World in Data COVID-19 dataset, 2021. Disponível em: https://ourworldindata.org/covidvaccinations. Acesso em: 20 abr. 2021.

SADOFF, Jerald et al. Safety and efficacy of single-dose Ad26. COV2. S vaccine against Covid-19. New England Journal of Medicine, 2021.

SANTOS, Maria Carolina. Tudo o que você queria saber sobre vacinas contra a covid-19 e não tinha a quem perguntar. 2021. Disponível em: $<$ https://marcozero.org/tudo-o-que-voce-queria-saber-sobrevacinas-contra-a-covid-19-e-nao-tinha-a-quem-perguntar/>. Acesso em: 18 abr. 2021.

SECRETARIA DE SAÚDE DO ESTADO DO CEARÁ. Quais os mecanismos de ação das vacinas disponíveis. 2021. Disponível em: <https://coronavirus.ceara.gov.br/quais-os-mecanismosde-acao-das-vacinas-disponiveis/\#: :text=A\%20vacina $\% 20$ CoronaVac $\% 20 \% \mathrm{C} 3 \% \mathrm{~A} 9 \% 20$ composta,anticorpos)>. Acesso em: 18 abr. 2021.

WHO. COVID-19 Weekly Epidemiological Update: Data as received by WHO from national authorities, as of 11 April 2021, 10 am CET. [S. 1.], 2021. Disponível em: <https://www.who.int/ publications/m/item/weekly-epidemiological-update-on-covid-19---13-april-2021>. Acesso em: 20 abr. 2021.

WHO. Update on COVID-19 vaccine development, Dez 2020. Disponível em: <https://www. who.int/docs/default-source/coronaviruse/risk-comms-updates/update45-vaccines-developement. pdf?sfvrsn=13098bfc_5>. Acesso: 17 abr. 2021. 


\section{Índice Remissivo}

$\mathbf{A}$

Acesso aos psicólogos 201, 203, 204

Acesso às redes sociais 43

Agricultor e o consumidor 260

Agricultores familiares 260, 263, 266

Alterações do metabolismo 115

Ambiente virtual 215

Ansiedade 77, 78, 81, 82, 83, 84, 86, 87, 91, 92, 94, 95, 117, 121, 190, 192, 193, 194, 197, 204, 207, 208, 209

Aplicativo 136, 215, 217, 218, 219, 220, 221, 222, 223, 224, 225, 226, 227, 228, 243, 271, 272, 273, 274, 278, 280

Aprendizagem 239

Assistência social 163, 171, 205

Associação da covid-19 com a gestação 52

Astrazeneca (universidade de oxford) 28, 30

Atenção primária 25, 124

Atenção primária à saúde (aps) 19, 59, 107, 125, 177, 178

Atendimento ambulatorial 105

Atendimento on-line 201, 203

Atendimento remoto 202, 205

Atividades econômicas 28

Autoanticorpos 250

Autoridades sanitárias 67, 69, 73, 278

C

Capacidade de defesa do organismo 115

Características dos imunizantes 28, 30

Cartilha educativa sobre a covid-19 67, 69, 70

Ceratoconjuntivite sicca $(\mathrm{kcs}) 250$

Combate à hanseníase 133

Comercialização 38, 260, 261, 262, 263, 264, 265, 266, 267, 268, 269

Compulsão alimentar 90, 92, 93, 94, 95, 96

Consumo de alimentos 105

Contaminação 43, 44, 45, 47, 49, 72, 73, 74, 78, 117, 135, 179, 191, 193, 195, 197

Coronavac (sinovac) 28, 29

Cuidados individuais e coletivos $67,69,73$

Cuidados preventivos ao covid-19 115

D

Depressão 78, 81, 82, 83, 87, 91, 92, 94, 95, 110, 172, 190, 192, 193, 194, 197, 207, 208, 209

Desemprego 21, 99, 103, 153

Desenvolvimento do câncer 177, 185

Desigualdade em saúde 163

Desinformação 29, 208 
Diabetes 21, 56, 57, 95, 105, 106, 107, 108, 114, 116, 117, 118, 119, 120, 181, 183, 186

Direito humano à alimentação adequada 103, 260

Disseminação da informação 67,73

Distanciamento social 25, 48, 55, 61, 68, 73, 90, 95, 126, 130, 192, 195, 202, 279

Distúrbios psicológicos 190

Doença infecciosa 53, 125, 133, 134, 140, 141, 151, 152

Doença multifatorial 250

Doenças 21, 24, 28, 29, 43, 54, 56, 57, 59, 69, 91, 95, 106, 107, 108, 115, 116, 117, 119, 120, 129, 133, 137, 140, 142, $149,161,163,164,167,171,172,173,177,185,186,193,194,195,207,210,217,222,223,227,250,271$, $272,273,278,279$

Doenças crônicas 105, 171, 218, 221, 227, 273

Doenças negligenciadas 140, 142

\section{$\mathbf{E}$}

Educação em saúde 19, 24, 43, 46, 48, 50, 67, 69, 73, 105, 108, 133, 134, 135, 136, 137, 145, 179, 185, 215, 216, 217, $227,228,238,240,248,271,272,274$

Efeitos colaterais $28,30,31,32,33$

Enfermagem 50, 56, 57, 58, 60, 61, 88, 89, 122, 149, 161, 176, 177, 178, 180, 188, 227, 240, 280

Enfermidade epidêmica 238

Enfrentamento da covid-19 18, 19, 20, 23, 24, 25

Epidemiologia 114, 140, 148, 149, 160, 161, 242, 248

Equipamentos de proteção 24, 43, 47, 78, 171, 197

Equipes multiprofissionais $52,54,55,56,59,60,61,62$

Estratégia saúde da família (esf) 18, 19, 23, 54

Estratégias nutricionais 105

Estresse 77, 78, 81, 82, 83, 86, 87, 88, 89, 94, 172, 190, 192, 193, 197, 206, 207, 209, 210, 211

Etiologia autoimune 250

Evidências científicas 29, 52, 56, 57, 59, 61, 62, 63, 76, 79, 99, 101, 190

F

Feiras agroecológicas 260, 261, 264

Ferramenta tecnológica de saúde 215

Fortalecimento da saúde púbica 67

Frequência cardíaca 230

G

Gestação 52, 53, 54, 57, 58, 59, 61, 62, 63, 224

Glândulas exócrinas 250, 251, 252, 253

Guia alimentar 105, 107, 108, 112, 113

$\mathbf{H}$

Hábitos alimentares 90, 92, 94, 95, 111, 112

Hanseníase 124, 125, 126, 127, 128, 130, 131, 133, 134, 135, 136, 137, 138, 139, 140, 141, 142, 143, 144, 145, 146, $147,148,149$

Herança genética 115

Hipertensão 57, 95, 105, 107, 108, 114, 115, 116, 118, 119, 120, 121, 181, 183, 186, 228, 229, 274, 276,278 
Hiposecreção lacrimal 250

I

Idosos 19, 21, 23, 54, 105, 108, 134, 137

Impacto da pandemia 99

Imunização 28, 29, 30, 35, 38, 179, 183, 186

Inclusão 20, 22, 52, 55, 56, 58, 75, 77, 79, 101, 163, 165, 167, 215, 226, 268

Infecções 28, 29, 38, 43, 44, 48, 57, 59, 60, 78, 165, 172, 180, 227, 251

Infecções respiratórias virais $43,44,48$

Informação de qualidade 271, 279

Informação em saúde 67,69

Informação sobre a hanseníase 124

Instabilidade econômica 99, 103

Instrumento de prevenção 43

Intervenção psicológica 202

Isolamento $23,48,55,60,62,81,90,91,92,94,100,142,164,177,179,190,191,192,193,194,195,196,197,198$, $199,203,204,205,207,208,210,242,261$

Isolamento social 23, 26, 62, 90, 92, 94, 100, 142, 164, 177, 179, 190, 191, 192, 194, 195, 196, 197, 198, 203, 205, 207, 208, 210, 242

$\mathbf{J}$

Janssen (johnson \& johnson) 28, 29, 30

$\mathbf{L}$

Lesões cutâneas 140, 143

Linha de frente 76, 78, 79, 81, 84, 86, 87, 88, 171, 195, 197, 202, 206, 207, 208, 210

M

Má qualidade do sono 77,87

Máscaras faciais 43

Material digital 43, 46

Medição biométrica 230

Medidas de isolamento 26, 28, 194

Medidores de glicose 230

Metodologia pico (problema, intervenção, contexto, resultado) 76, 79, 99, 101

Monitores do centro de ciências da saúde (ccs) 238

Monitoria 238, 239, 240, 241, 242, 243, 244, 246

Morbidade 115, 119

Mortalidade materna 163, 171, 172

Mudanças nos estilos de vida 90, 92, 93

Mycobacterium leprae 135, 140, 141, 146

N

Níveis socioeconômicos 43, 46

Novas modalidades de interações 238

Novo coronavírus sars-cov-2 18, 19 
Olho seco 250, 251, 252, 253, 254, 255, 256, 257, 258

Organização mundial de saúde (oms) 19, 52, 53, 54, 68, 92, 191

Organização pan-americana de saúde (opas) 52, 54

Órgãos oficiais de saúde 238, 247

Outubro rosa $177,178,179,184,185$

$\mathbf{P}$

Padrões dietéticos 115

Pandemia 18, 19, 20, 21, 23, 24, 25, 26, 28, 31, 38, 45, 47, 48, 53, 55, 68, 69, 73, 75, 76, 78, 79, 81, 82, 84, 86, 87, 88, $89,90,91,92,93,94,95,96,99,100,101,102,103,104,117,118,119,120,124,126,130,131,133,135,136$, $137,142,152,153,160,161,162,163,164,165,168,169,170,171,172,173,174,177,179,180,186,187$, 190, 191, 192, 193, 194, 195, 196, 197, 198, 199, 200, 203, 204, 205, 206, 207, 208, 210, 211, 212, 213, 238, $239,240,241,242,244,247,248,271,272,279,280$

Perfil alimentar 105

Perfil clínico 160, 177, 183, 185

Pfizer (pfizer e biontech) 28, 30

Políticas públicas de saúde 18, 24, 173, 204

Portadores de síndrome metabólica 115

Prática oftalmológica 250

Práticas do autocuidado 178,186

Pressão arterial 115,230

Prevenção 29, 33, 72, 170, 187, 221

Primeiros socorros 215, 218, 219, 225, 227, 273

Princípio ativo 28, 30, 33

Produção de alimentos 260

Profissionais de psicologia 202

Profissionais de saúde 18, 22, 24, 54, 56, 76, 78, 79, 81, 82, 84, 85, 86, 87, 89, 107, 125, 138, 151, 160, 170, 185, 194, $195,197,198,202,206,207,208,238$

Programa nacional de alimentação escolar (pnae) 99, 265

Promoção em saúde 43, 45, 271, 278

Propagação do vírus $43,47,48,67,69$

Q

Qualidade de vida 22, 47, 82, 106, 112, 155, 217, 226, 244, 250, 251, 254, 272, 278

Quarentena 90, 100, 121, 126, 170, 172, 190, 191, 192, 193, 194, 195, 199, 202, 206

$\mathbf{R}$

Recurso tecnológico 230

Redes sociais 43, 45, 46, 49, 133, 137, 194, 271, 272, 274, 278, 279

Responsabilidade individual e coletiva 18, 24

Restrição social 90, 92, 93 
Sars-cov- $20,21,29,30,31,32,33,34,35,38,39,40,45,49,53,56,57,58,59,60,65,88,120,163,164,165,168$, $173,191,199,238,239,240,242,243,247,248,279$

Saúde da família 18, 19, 20, 22, 23, 24, 25, 26, 52, 54, 55, 62, 64, 125, 135, 179, 187

Saúde da mulher 163, 166, 173

Saúde de maneira remota 133

Saúde dos profissionais $76,79,81,86,89$

Saúde dos trabalhadores $77,86,87$

Saúde integral 52, 163, 165, 167, 171

Saúde mental 78, 83, 88, 90, 93, 94, 95, 96, 172, 179, 190, 191, 192, 193, 194, 195, 196, 197, 198, 202, 203, 204, 206, $207,208,210,212,222,227,279$

Saúde psicológica 77,87

Saúde pública $6,20,28,38,69,73,82,120,125,134,139,141,148,149,160,168,169,170,171,172,177,179,197$, $199,208,211,238,240,242,247$

Secura ocular 250, 251, 257

Sedentarismo 94, 107, 115, 179

Segurança alimentar e nutricional 99, 100, 101, 102, 103, 104

Segurança alimentar nutricional (san) 99

Serviço de saúde 71, 115, 120, 180

Síndrome de sjögren (ss) 250, 251

Síndrome metabólica 115, 116, 117, 118, 119, 120

Sistema imunológico 58, 115, 117, 120

Sistema nacional de agravos de notificação (sinan) 140, 143

Situação de vulnerabilidade 90, 94, 95, 103

Superfície ocular 250, 254, 258

T

Tecnologia 66, 67, 69, 70, 137, 211, 231, 244

Tecnologias de informação e comunicação 208, 230

Teleatendimento 202, 204

Telemedicina 133, 170, 230, 232

Telessaúde 230, 236

Tempos pandêmicos 271

Terapêutica multidisciplinar 190

Teste de schirmer 250, 255

Testes oftalmológicos 250

Transmissão de informações 271, 279

Transtorno de ansiedade generalizada 190, 192

Tuberculose (tb) 151,152

$\mathbf{U}$

Unidade de saúde da família (usf) 52, 55

Uso das máscaras 43, 45, 48 
Vacina 28, 31, 32, 33, 34, 37, 39, 40, 70, 72, 159, 161, 183, 184, 186, 221

Variantes $28,30,31,34,35,38,49,78$

Vídeos educativos 215, 226

Violência contra a mulher $163,169,170,173,174$

$\mathbf{X}$

Xeroftalmia 250,251 


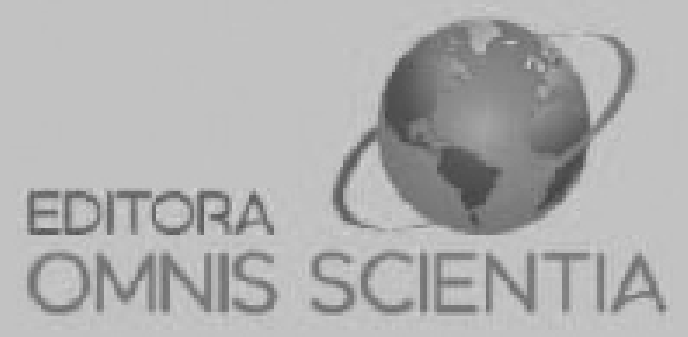

editoraomnisscientia@gmail.com M https://editoraomnisscientia.com.br/ @editora_omnis_scientia (0) https://wwww.facebook.com/omnis.scientia.9 $\boldsymbol{\oplus}$ +55 (87) 9656-3565 (C) 


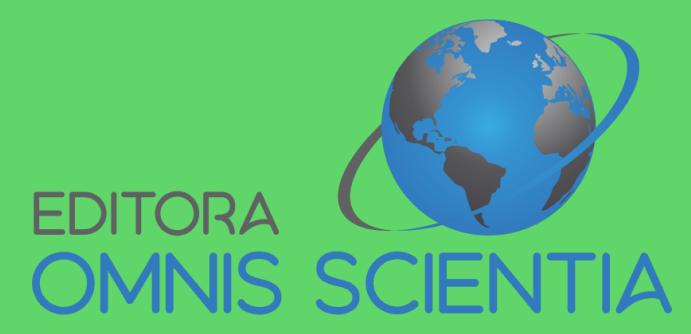

editoraomnisscientia@gmail.com M https://editoraomnisscientia.com.br/ (-) @editora_omnis_scientia (0) https://www.facebook.com/omnis.scientia.9 $\subsetneq$ +55 (87) 9656-3565 @ 